\title{
China's Agri-trade Deficit Under the BRI
}

\author{
Meixi Peng ${ }^{1 *}$ \\ ${ }^{1}$ College of Finance, Capital University of Economics and Business, Beijing 100070, China \\ Corresponding Author's Email:michelle1999118@hotmail.com
}

\begin{abstract}
The Belt and Road Initiative (BRI) has been playing an increasingly important role in international trade since its proposal in 2013. Meanwhile, though China has implemented various policies to address its ongoing, increasing agri-trade deficit, policy effects have been partially offset by a number of counteracting factors. This paper seeks to identify these factors and propose solutions to address them, in hope of rendering future government policies more effective in addressing the agri-trade imbalance.
\end{abstract}

Keywords : Belt and Road, Agriculture, China agri-trade deficit

\section{INTRODUCTION}

The Belt and Road Initiative was first announced in fall 2013, by President Xi Jinping of the People's Republic of China. It aims to stimulate economic growth by linking China to Europe through Southeast Asia, Central Asia and the Middle East, and addresses multiple issues such as trade, investment, infrastructure, finance and more. Meanwhile, contrary to China's ongoing current account surplus, its agri-trade has seen a persistent, increasing deficit since 2004, which threatens the nation's food security and price stability while disrupting industry structure and sectional growth. Despite having implemented a series of policies addressing agricultural issues, China's agri-trade deficit is worsening.

Understanding why these policies have not been fully effective in improving China's deficit is important because only by identifying and coping with these matters can governments effectively address national issues. Additionally, the BRI is in its initial stage of development, during which government guidance is key to structural formation. Should policies be ineffective in this crucial process, the BRI may develop fundamental problems and fall into obsolescence, annihilating its potential to boost global trade and wealth.

This paper seeks to render government policies more effective in addressing agri-trade by analyzing China's policies against the background of the BRI and China's current agricultural conditions, identifying the factors that offset policy effect and finally proposing corresponding solutions.

\section{AN ANALYSIS OF CHINA'S PRESENT AGRICULTURE}

Despite 12 years of continuous agricultural output growth, China has been in an increasing agri-trade deficit since 2004. To illustrate, in 2017 China's agricultural trade deficit was over 50 billion USD with a sequential growth of over $30 \%^{[16]}$, and had reached 71.87 billion USD in 2019, with 54.24 billion occurring from 57 out of 63 BRI economies. The reasons for this ongoing deficit can be analyzed from three angles: China's agricultural environment, exports and imports, and other relative perspectives.

\subsection{Agricultural Environment}

Severe environmental restraints render China's agricultural development increasingly difficult ${ }^{[9]}$. China is deficient not only in high-quality arable land, but also in agricultural reserves. Moreover, China faces uneven distribution in both farmland and water resources, as well as many environmental problems such as land degradation, desertification, pollution and encroachment on arable land.

Furthermore, China is accustomed to an outdated agricultural production mode. Its labor-intensive, traditional, small-scale, family-based production method is unorganized, inefficient and unregulated, and has resulted in a low agricultural productivity of only $1 / 50$ that of the average developed country ${ }^{[9]}$. Such production 
cannot meet China's growing agricultural demand, and renders China's agricultural industry in desperate need to shift towards "mechanized production, industrialized organization and standardized manufacturing "[8].

\subsection{Exports and imports}

Although the belt-and-road initiative has enhanced trade between China and BRI participants, the number of China's main agri-trade partners is still very limited. Exports to countries such as Russia, Thailand, Malaysia and Indonesia take up 50\% of China's total agri-exports, while countries such as Thailand, Malaysia, Indonesia and India account for more than $70 \%$ of China's agri-imports $^{[6]}$. This uneven trade structure limits China's access to new markets and raises supply-and-demand risk. Additionally, China's agri-exports consist mainly of fruit and vegetables, and relies heavily upon low price. However, with a severe depletion of the agricultural population during the past two decades and lack of other competitive edges, China's production costs of fruit and vegetables have been rising, which in turn has weakened competitiveness.

Increasing import demand is also an important issue. An increasing population, together with rising living standards, contributes to China's increasing demand for high-quality agri-products, which domestic growth cannot catch up with. Consequently, the country can only increase imports, further suppressing domestic agricultural production ${ }^{[6]}$, and creating a vicious cycle. China's continuous agri-trade deficit that renders it ever-more reliant upon imports ${ }^{[8]}$, which can be easily impacted by external shocks such as price changes, government policies and regional politics. This directly threatens China's national security through food supply and price levels.

\subsection{Other perspectives}

Further constraints upon China's agricultural production include outdated agricultural infrastructure, relatively low levels of agri-tech and low farmer-education levels. On one hand, China lags behind not only in modern agricultural infrastructure and equipment, but also in agricultural services such as maintenance, fitting and supply of equipment, which makes modernization difficult. On the other hand, poorly educated farmers would be unable to operate modernized infrastructure and equipment even if acquired, due to inadequate education. Lack of scientific and market awareness keeps most Chinese farmers from integrating advanced agricultural knowledge into their production or employing sophisticated management techniques, and has resulted in China's stagnant agricultural modernization.

Additionally, China's agri-tech level 15 to 20 years behind that of advanced nations (Chinese Academy of
Agricultural Sciences). Inadequate funding has contributed to an agricultural researcher-to-population ratio of almost $50 \%$ beneath world average and has constrained most agri-tech accomplishments to academia, leading to a transformation rate of scientific research of roughly $20 \%$ to $30 \%$ lower than that of the average developed country, resulting in inadequate scientific reserves $^{[9]}$

\section{POLICY EVALUATION}

Since the proposal of the BRI, China has imposed various policies addressing agricultural challenges, which can be categorized into domestic policies and foreign policies. Due to the transnational nature of the BRI, this paper focuses upon foreign policies and their effects

\subsection{Domestic Policies}

China's recent agricultural policies have focused upon improving agricultural infrastructure, easing environmental constraints and pushing forward industrial development and rural reformation, and the effects can be evaluated from four perspectives: preservation of resources, modernization of infrastructure, construction of eco-systems and improvement of farmers' living conditions.

The establishment of 255 million acres of "permanent farmland" (land bound by law for agriculture use only), designation of 178 million acres of land for the cultivation of important agri-products and 132 million acres of high-standard farmland, as well as construction of 52 national seed-production counties and 100 regional breeding-bases has effectively safeguarded China's national production. Successive decreases of pollution and increased production of eco-friendly, high-quality products show that efforts to build a sustainable agricultural eco-system have generated positive results. Average disposable income of the rural population, with its tenfold increase in 10 years and growth rate exceeding that of the urban population for 11 successive years, accurately portrays improvement of farmers' living standards. Moreover, integration of science and technology, together with generalization of modern facilities, has significantly boosted agricultural production. Therefore, it is safe to say that domestic policies have yielded desirable results.

\subsection{Foreign Policies}

\subsubsection{Policy descriptions}

China's current foreign policies, of which the BRI is one of the most significant components, mainly addresses agriculture through four issues: cooperation, trade, infrastructure and capital flow. 
Visions and Actions on Jointly Promoting Agricultural Cooperation on the Belt and Road, issued in May 2017, offered a blueprint for BRI cooperation. It promoted utilizing differences between BRI economies through cooperation in order to maximize global efficiency and felicity. Cooperation is further emphasized in China's "Going Global" strategy, which stresses mutual benefit by taking into consideration the overall development of BRI economies. Such policies not only seek to increase trade and productivity, but also address poverty, food security, living standards and underdevelopment in BRI economies, and are key to tap into cooperation potential.

China has also implemented a series of policies aiming to improve trade environment. In 2018, China announced that it will promote cross-border e-commerce, digitalize international bills of lading and upgrade domestic infrastructure so as to better align with BRI transportation networks. China then implemented 22 measures easing restriction upon market access while taking measures to standardize approval processes, simplify custom procedures and cancel unnecessary requirements of international trade. These policies aim to either increase trade convenience through digitized, standardized and simplified procedures, or create trade incentives through easier market access, both with the goal of boosting efficiency and volume of trade.

Moreover, China has sought to improve BRI infrastructure through various methods such as investment, aid, and joint construction projects. As enterprises play the main role in BRI agricultural cooperation, China has built platforms for transnational agricultural businesses while encouraging them to invest in production bases overseas. Such efforts to improve infrastructure not only aim to boost agricultural productivity, increase safety and efficiency of transportation, stimulate growth in sectors such as manufacturing, infrastructure, power generation and logistics, create jobs, promote structural transformation, but also addresses common problems regarding infrastructure in BRI economies such as lack of government funds, all of which facilitate merchandise trade and economic development.

Financial cooperation between BRI economies is key in addressing current predicaments such as high credit risk, insufficient financial resources, high cost and low efficiency of capital, for it enables countries to coordinate capital to promote efficiency. To this end, China seeks to "deepen financial connections while exploring new forms of international investment". In April 2018, The government issued Opinions on guiding the healthy development of foreign investment and financing funds, which declared that China would guide domestic investors towards foreign markets to provide a "long-term, stable, sustainable, risk-controllable" source of capital and offer support to large companies financing overseas. In both 2018 and 2019, China cut back restrictions on foreign investment and issued documents protecting the rights of foreign investors and encouraging them to invest in specific industries such as modern agriculture, advanced manufacturing, high tech areas and modern service industries. It can clearly be seen that these policies can be viewed as efforts to attract foreign investors and pushing financial and sectional growth through the utilization of foreign capital.

\subsubsection{Policy evaluation}

The effects of these foreign policies can be evaluated from three aspects: volume of trade between BRI economies, infrastructure development and financial cooperation.

Since the presentation of the BRI in 2013, China's bilateral trade volume with BRI economies has risen to unprecedented levels. In only seven years, China's total trade volume with BRI economies has seen an increase of almost 50\%, from 6.5 trillion RMB in 2013 to 9.4 trillion RMB in 2020. Under such circumstances, agri-trade has also seen rapid development in the past years, specifically through the rapid increase in trade volume, increased proportion in total trade and development of trade networks.

China's agri-trade volume with BRI economies has seen a substantial $24.82 \%$ increase from 2013 to 2018, by far exceeding China's total increase in agri-trade volume of $17.01 \%{ }^{[10]}$. Agri-trade is also accounting for an increasing portion of trade between BRI economies, rising from $22.39 \%$ in 2013 to $23.88 \%$ in 2018 . Furthermore, in 2020, while trade volume between China and BRI economies took up $27.4 \%$ of its total trade volume, agri-trade volume between China and BRI economies took up $35.1 \%$ of its total agri-trade volume, indicating that agri-trade is playing an increasingly important role in the BRI. Additionally, variety of agri-products between BRI economies have sequentially increased since the initiative was presented (the Agricultural Trade Promotion Center). These facts show that recent policies have successfully spurred BRI agri-trade.

Consequently, networks between BRI economies have become increasingly complex. As more and more join the initiative, economies are bound ever more tightly together through both dependency and competition, and with research showing that agricultural complementary networks outweigh competitive networks between BRI economies ${ }^{[5]}$, potential for further cooperation exists. Therefore, governments have together initiated plans to increase scales of transnational operations and work towards "full strategic coordination" [3]. Meanwhile, China has established various agricultural cooperation measures including investment, technology and trade with Central Asian 
economies, and has also created platforms, opportunities and safety nets for agri-trade with African economies.

China's investments in BRI infrastructure has also yielded impressive results. In 2014, Chinese premier Keqiang Li, along with the Heads of State from four East African countries, witnessed the signing of the loan agreement for the Mombasa-Nairobi Standard Gauge Railway project, Kenya's first and largest infrastructure project since independence. In 2015, China collaborated with Indonesia to launch Southeast Asia's first high-speed rail project, the Jakarta-Bandung railway. In 2016, President Hassan Rowhani attended the commencement ceremony of the Teheran Mashhad Railway electrification transformation project, which was jointly managed by Chinese and Iranian enterprises. Such business operations under government sponsorship represent an innovative approach to international cooperation, and opens a new door for BRI cooperation.
Furthermore, the development of BRI infrastructure has significantly increased market efficiency. China-Europe freight trains now connect 16 countries and 113 cities, and up to 2018, China has signed Bilateral Governmental Air Services Agreements with 126 countries, increased its number of international airlines by more than $69 \%$, and has signed 18 International Multilateral Transport Facilitation Agreements and 38 Bilateral and Regional Maritime Agreements with 47 BRI economies. Infrastructure improvements brought about by the BRI has effectively increased trade volume and efficiency ${ }^{[2]}$, boosted the overall level of direct investment and accelerated economic developments, as illustrated in Figure $1^{[2]}$, which shows the effects of infrastructure upon GDP of BRI economies.

\section{Increase in GDP due to Infrastructue}

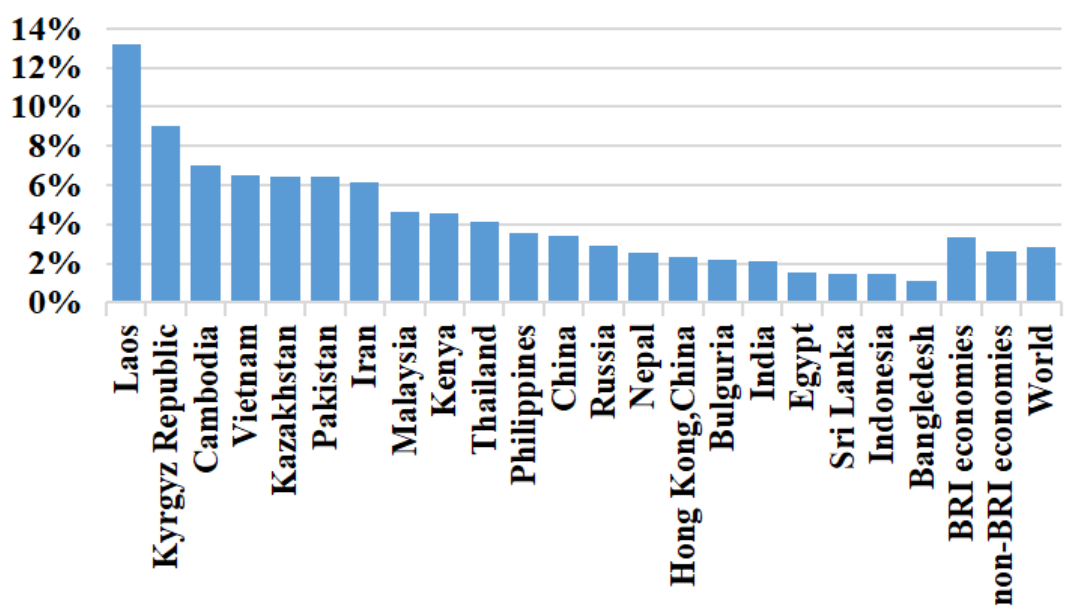

Figure 1. Effects of infrastructure upon GDP

Additionally, the BRI has lead to reductions in average trade costs by up to $2.81 \%$ in BRI economies and $2.19 \%$ globally ${ }^{[1]}$. Table 1 shows the effects of infrastructure upon bilateral trade costs of different regions.

Table 1. trade cost reductions due to infrastructure

\begin{tabular}{|c|c|c|c|c|c|c|c|}
\hline & $\begin{array}{l}\text { East Asia } \\
\& \text { Pacific }\end{array}$ & $\begin{array}{c}\text { Europe \& } \\
\text { Central } \\
\text { Asia }\end{array}$ & $\begin{array}{c}\text { Latin } \\
\text { America } \\
\& \\
\text { Caribbean }\end{array}$ & $\begin{array}{l}\text { Middle } \\
\text { East \& } \\
\text { North } \\
\text { Africa }\end{array}$ & $\begin{array}{c}\text { North } \\
\text { America }\end{array}$ & South Asia & $\begin{array}{l}\text { Sub-Sahar } \\
\text { an Africa }\end{array}$ \\
\hline $\begin{array}{c}\text { East Asia \& } \\
\text { Pacific }\end{array}$ & $1.46 \%$ & $2.42 \%$ & $0.64 \%$ & $2.50 \%$ & $0.96 \%$ & $3.55 \%$ & $2.19 \%$ \\
\hline $\begin{array}{c}\text { Europe \& } \\
\text { Central Asia }\end{array}$ & $2.39 \%$ & $0.91 \%$ & $0.72 \%$ & $0.32 \%$ & $0.70 \%$ & $0.74 \%$ & $0.95 \%$ \\
\hline $\begin{array}{l}\text { Latin America } \\
\& \text { Caribbean }\end{array}$ & $0.65 \%$ & $0.71 \%$ & 0 & $0.04 \%$ & 0 & $1.08 \%$ & $0.51 \%$ \\
\hline $\begin{array}{c}\text { Middle East \& } \\
\text { North Africa }\end{array}$ & $2.69 \%$ & $0.31 \%$ & $0.04 \%$ & $0.11 \%$ & $0.17 \%$ & $0.56 \%$ & $0.79 \%$ \\
\hline $\begin{array}{l}\text { North } \\
\text { America }\end{array}$ & $0.99 \%$ & $0.66 \%$ & 0 & $0.15 \%$ & 0 & $1.21 \%$ & $0.41 \%$ \\
\hline South Asia & $3.84 \%$ & $0.81 \%$ & $1.06 \%$ & $0.57 \%$ & $1.32 \%$ & $3.17 \%$ & $2.30 \%$ \\
\hline $\begin{array}{l}\text { Sub-Saharan } \\
\text { Africa }\end{array}$ & $2.40 \%$ & $1.03 \%$ & $0.53 \%$ & $0.85 \%$ & $0.45 \%$ & $2.44 \%$ & $0.86 \%$ \\
\hline
\end{tabular}




\section{OBSTRUCTIONS AND SOLUTIONS}

\subsection{Obstructions to government Policy}

Though China's policies have to some extent generated desired results, they have not yet reached their full potential due to a number of obstructions which need to be solved in order to render government policies most effective and unlock the full potential of cooperation. These factors can be divided into external factors and internal factors.

\subsubsection{External Factors}

External factors refer to problems outside the control of individual corporations that counteract government efforts. These problems consist of five major categories: lack of reliable service, high risk, inadequate capital flow, conflicts of national interest and lack of infrastructure.

Firms must have sufficient capital and be able to convert this capital into foreign currency whenever economic turbulence occurs in order to survive. However, this typically involves large amounts of capital and requires complicated approval processes that call for various service corporations such as financial intermediaries, law firms, accounting firms and more ${ }^{[4]}$. Currently, however, the majority of transnational service agencies operating in BRI economies can only provide limited service, leaving transnational companies no choice but to turn to foreign firms that are likely unwilling to offer sufficient support. This not only directly impacts capital flow of business operations, but also increases uncertainty and risk associated with transnational operations, repelling investors and hence counteracting government efforts to improve investment environment.

Moreover, political instability within many BRI economies discourages transnational operations. In politically unstable environments, transportation is unsafe and previous agreements may be announced invalid overnight, causing heavy losses to firms. Generally, BRI economies rank low in the Doing Business report by the World Bank Group, indicating high risk and instability, which obstructs agricultural cooperation. Furthermore, not only is commercial risk such as political, environmental, market, safety and legal risk high in BRI economies ${ }^{[12]}$, but as is credit risk. Moody's Creditview lists that 42 BRI countries fall below investment grade or even outside its rating scope. Such risks weaken competitiveness of BRI economies and therefore obstructs transnational cooperation.

In addition, the majority of BRI economies are developing nations unable to bear the risk associated with free capital flow, and hence impose various restrictions on foreign investment. This has resulted in high cost of transnational investments. Furthermore, existing investments exhibit severe imbalances in structure. More than $80 \%$ of total transnational BRI investments flow towards a few select regions ${ }^{[2]}$, as shown in Figure 2.. While high cost repels investors, uneven capital distribution may cause dissatisfaction and reluctance to further cooperation, offsetting government efforts to increase capital flow.

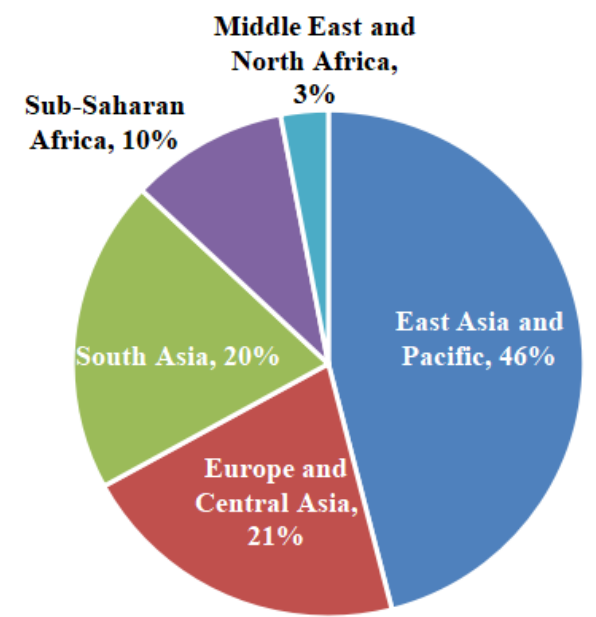

Figure 2. Regional Percentage Shares of Total Transportation Infrastructure

Furthermore, differences in aspects such as culture, political systems and levels of development causes conflicts of interest in BRI cooperation, which can be analyzed from two main angles: subsidies and trade barriers.

As interactions between BRI economies rise, so does competition. A number of governments have began to subsidy local railway and freight companies in order to boost competitiveness, causing cutthroat competition. Similarly, increasing trade barriers has impeded upon agri-trade: many countries have imposed trade sanctions in recent years, which has inevitably obstructed agri-trade development: in 2016, 32 out of 65 BRI economies had proposed a total of 729 Technological Barriers to Trade (TBT) and Sanitary and Phytosanitary Standards (SPS) notifications, an $8 \%$ increase from the preceding year, of which agri-products took up a $44.5 \%$ of total TBT notification ${ }^{\text {s[7] }}$, and China's agri-exports have faced increasing trade barriers. Additionally, as global living standards rise, so does product requirements. BRI economies such as Malaysia and Singapore have imposed strict inspection standards for agri-products, and China's exports have often been rejected for inadequate amounts of chemical fertilizer, pesticide residue and more ${ }^{[14]}$. Such barriers have caused terrible losses to export companies and obstructed agricultural cooperation, compromised economic growth $^{[13]}$ and may even cause national disputes if unresolved.

Lack of infrastructure also hinders agricultural cooperation. The majority of BRI countries are 
landlocked and far away from China, rendering shipment by sea, the optimal method for most large-scale transport, impossible and on-land logistics crucial. However, inadequate funding has resulted in poor quality of on-land infrastructure in many BRI countries such as Myanmar, Cambodia, and Laos ${ }^{[14]}$. Additionally, agri-products are more likely to spoil than other products, and requires efficient, high-quality transport. Hence, inadequate infrastructure counteracts government efforts to boost agricultural trade.

\subsubsection{Internal Factors}

Internal factors refer to issues regarding enterprise operations, which take direct responsibility for China's poor investment structure and low economic returns ${ }^{[17]}$, and in turn renders investors averse to BRI investments, counteracting government effort. To avoid over-complexity, the following analysis focuses upon one representative operation: Transnational Merging and Acquisition (TMA).

Present Chinese TMA show problems such as low rate of profit and high rate of loss. Statistics show that only $13 \%$ of Chinese TMA projects have generated adequate amounts of profit during the past five years, while up to $63 \%$ have experienced loss or at best, broke even. This is due to lack of TMA experience, which shows in four major aspects: lack of vision, mixed priorities, inadequate analysis and poor management ${ }^{[15]}$.

TMA requires corporations to have a lucid understanding of how the operation assists in achieving its long-term goal. However, many private Chinese corporations fail to consider long-term factors such as changes in market conditions and stability of revenues $^{[15]}$, causing future burdens that obstruct long-term growth.

Furthermore, when conducting TMA, the majority of Chinese companies pay inadequate attention to long-term performance, instead focusing upon factors such as short-term business-collaboration and low $\operatorname{costs}^{[15]}$. Such lack of foresight is likely to generate undesired results, as when Chinese tech group TCL merged French Thomson company in 2004. TCL's main motive was to cut back overall costs by integrating Thomson's tech and sales channels with its production, yet it failed to consider long-term factors such as its declining market, as well as Thomson's out-dated technology and ongoing deficit. This resulted in years of loss and a two-year slide of TCL stock price, rendering the operation one of the most classic TMA failures.

Another major shortcoming is inadequate corporation analysis ${ }^{[15]}$. As stated earlier, Chinese enterprises lack experience, and when conducting company analyses, are more likely to misinterpret or overlook important issues, resulting in faulty decisions. As in the previous example, TCL disregarded
Thomson's annual 130-million-euro-deficit and overestimated the economic benefits it would bring, which ultimately lead to massive losses in the coming years. Inadequate analysis can also result in unreasonable pricing, as when Chinese Shougang Group acquired Peru's largest iron ore producer, Hierro Perú, in 1992 , for a proposed price of 120 million USD, a price that exceeded all 37 bidders by an outrageous amount. Experts agree that considering factors such as infrastructure and transportation costs, the price proposed by Shougang by far too high ${ }^{[15]}$.

Management is also crucial to TMA success, specifically that of corporate culture (an unwritten set of rules and ideology that guide employee and business conduct). Differences in corporate culture lead to inefficiency and even conflict, and accounts for more than $80 \%$ of Merge\&Acquisition failures ${ }^{[11]}$. However, the concept of corporate culture is often brushed away as insignificant by Chinese businesses, which can be shown in both cases of TCL and Shougang. In the prior case, TCL emphasized keeping up with market change while Thomson payed greater attention to detail and product quality, causing conflict and frustration. Shougang failed to consider cultural differences and simply extended domestic management methods abroad, resulting in multiple Peruvian worker strikes which costed the company heavily.

\subsection{Solutions}

This section proposes measures to address the previously stated problems, which include lack of reliable service, high risk, inadequate capital flow, conflicts of national interest, lack of infrastructure, lack of vision, mixed priorities, inadequate analysis and poor management.

Governments can address the lack of adequate service by supporting expansions of transnational service agencies or collaborating with foreign governments to provide enterprises with sufficient service. Enhanced insurance policies can relieve high risk of investments, and conflicts of interest can be resolved through additional government cooperation such as modifying existing treaties and signing additional ones. If successfully implemented, risk and cost of transnational operations will decrease, nations will benefit from credible sources of tax income, and sustainable growth will be obtained as a result of healthy market competition.

Transnational enterprises, on the other hand, may play a large role in resolving internal issues. It would be beneficial for them to strengthen analyses of economic environments to minimize negative impacts of economic turmoil, to acquire high-quality teams to analyze important factors such as legal risk, policy risk, corporate finance, profitability and long-term effects of 
relevant operations and also to modify management tactics with consideration to both corporate and local culture to avoid potential conflict.

\section{CONCLUSION}

This paper finds that China's current agri-trade exhibits increasing external dependence and risk. Meanwhile, despite ongoing obstructions to agricultural cooperation, agri-trade is playing an increasingly important role in BRI trade, and economic benefits have rendered BRI economies keen to enhance cooperation. However, despite enhanced trade, China's agri-trade deficit has aggravated, which threatens food security and price levels. Therefore, it is of national importance for the government to address these stated issues. This paper then identifies and evaluates goals and effects of policies that impact China's agriculture, and finds that though both recent domestic policies and foreign policies regarding agricultural cooperation and BRI development have seen desirable results, their impacts have yet to reach their full capacity due to a number of factors that partially counteract government efforts, which can be categorized into factors outside the control of individual corporations and those regarding enterprise operation. While the prior consist mainly of lack of reliable service, high risk, inadequate capital flow, conflicts of national interest and lack of infrastructure, the latter includes lack of vision, mixed priorities, inadequate analysis and poor management.

These issues must be resolved for government policies to effectively address current issues. To this end, this paper proposes solutions to both governments and enterprises. It suggests that governments support existing transnational service agencies, timely modify existing treaties and extend collaborations with foreign governments in areas such as financial service, subsidies and tax. It recommends that transnational enterprises acquire high-quality teams to analyze commonly overlooked or misinterpreted factors such as the economic environment, legal risk, policy risk, cultural difference and profitability. Additionally, enterprises should place greater emphasis upon long-term effects of relevant operations and corresponding management tactics. Should these suggestions be adopted, not only will economic benefits emerge, both current and future government policies will also prove to be more influential.

It should be noted that this paper focuses upon independent government policies when conducting analyses and does not consider interactive relationships between them. It also focuses only upon agriculture when evaluating policy goals and effects, ignoring other aspects such as international relationships, welfare and trade accounts. Another shortcoming is that this paper uses TMA to account for all transnational operations conducted by Chinese enterprises, which is a simplifies complex issues. Future research can analyze comprehensive, interactive effects of government policies and provide more in-depth conclusions regarding their effectiveness. It may also be beneficial to study different types of transnational operations conducted by Chinese enterprises to obtain more insight upon how these operations can be improved.

\section{REFERENCES}

[1] De Soyres, F., Mulabdic, A., Murray, S., Rocha, N., \& Ruta, M.(2018).How Much Will the Belt and Road Initiative Reduce Trade Costs? (Policy Research Working Paper No.8614). World Bank Group.https://elibrary.worldbank. org/ doi/abs/10.1596/1813-9450-8614

[2] De Soyres, F., Mulabdic A., and Ruta M.(2019).Common Transport Infrastructure: A Quantitative Model and Estimates from the Belt and Road Initiative(Policy Research Working Paper No.8801).World Bank Group.https://elibrary. worldbank .org/doi/abs/10.1596/1813-9450-8801

[3] Jiang Y.,Ru L.,Yang G. and Chen R..Features and Prospects of Cooperation upon Agricultural Investment between China and the ASEAN[J].World Agriculture, 2019(6):12-16

[4] Liang J.. A Research on the Risks Chinese Companies Face During Transnational Merge and Acquisition under the "Belt and Road" Initiative[J].Tax Paying,2019(34):183,185.

[5] Liu C , Xu J , Zhang H . Competitiveness or Complementarity? A Dynamic Network Analysis of International Agri-Trade along the Belt and Road[J]. Applied Spatial Analysis and Policy, 2019(1)

[6] Luo H..A Research on the Effects of Agricultural Trade upon Growth of Agricultural Economics in Belt and Road Economies[J].Agricultural Economy, 2019, 000(001):131-133.

[7] Nong X.. Agricultural Trade Barriers and China's Coping Mechanisms under "Deglobalization" [J]. Economic Relations and Trade,2018(4): 40-43.

[8] Pan W..Microcosmic Explanations of Trade Effects of Agricultural FDI--A Research Based upon China and " Belt and Road" Economies[D].Zhejiang University,2018.

[9] Shi Z..Major Problems Regarding Agricultural Modernization with Chinese Characteristics[J]. Nongjia Zhifu Guwen, 2019(6):135-135.

[10] Sun z.,Li X. and Li S.Agricultural Intra-Industry Trade Between China and Countries Along the 
" Belt and Road " and Its Influencing Factors[J].Journal of Huazhong Agricultural University(Social Sciences Edition), 2021(1):57-68+176.

[11] Vasconcellos G.M., Madura J., Kish R.J..An empirical investigation of factors affecting cross-border acquisitions: the United States vs. United Kingdom experience[J].Global Finance Journal,1990,1(3):173-189.

[12] Wang Y. A Measurement Analysis of Energy Cooperation Risk under the "Belt and Road" Initiative[J]. Guangxi Quality Supervision Guide Periodical, 2021(2):224-225.

[13] Wang T. Suggestions of Development Strategies for Regional Economic Logistics under the "Belt and Road" Initiative[J].Market Observer, 2020(06):60.

[14] Xu C. and Zhao X. The Current State, Problems and Prospects of Agricultural Cooperation Between China and "Belt and Road" Economies[J]. Agricultural Economy,2018, 000(010):130-131.

[15] Yao Z. Problems and Measures of Development Regarding Transnational Merge and Acquisition conducted by Chinese Enterprises[J].Study and Practice, 2007(09):36-39.

[16] Yu J..A Research on China's Strategic Orientation of Agricultural Foreign Trade under International Agricultural Cooperation of the "Belt and Road" Initiative[J].Agricultural Economy, 2020(3): 126-128.

[17] Zhou X. Economic and Financial Effects of the "Belt and Road" Initiative[J].China Circulation Economy,2020, No.2234(02):166-167. 